日消外会誌 $34(6): 615 \sim 618,2001$ 年

症例報告

\title{
Frey 手術が奏効した膵気管支瘻合併が示唆された慢性膵炎の1例
}

\begin{tabular}{|c|c|c|c|c|c|}
\hline \multicolumn{6}{|c|}{ 山口大学第 1 外科 } \\
\hline 藤夫 & 雅和 & 榎 & 忠彦 & 中屋敷千鶴 & 井口 \\
\hline 小林 & 哲郎 & 野島 & 真治 & 江里 健輔 & \\
\hline
\end{tabular}

\begin{abstract}
症例は40歳の男性 . 主訴は背部痛, 呼吸困難 .アルコール性慢性膵炎の加療中, 背部痛, 乾性咳嗽 を自覚し，精査の結果仮性脺囊胞の縦隔進展，膵石と診断された。保存的治療で改善しないため手術 目的で外科紹介となった .内視鏡的逆行性膵管造影では膵頭部に9x $6 \mathrm{~mm}$ の膵石を認め，弚の体部側 に主膵管に連続する囊胞が造影された．腹部正中切開の後，盲囊を横切開し，膵藏を露出した . 超音 波ガイド下に主膵管を確認した後，膵石を含む膵頭部部分切除，膵管空腸側々吻合術を施行した . 術 後は経過良好で，経口摂取開始後，なんら自覚症状は出現しなかった . 術後第31病日軽快退院した 。 術後コンピューター断層撮影では縦隔内仮性脺囊胞は消失し， HbA $105.7 \%$ と耐糖能は良好であった 。
\end{abstract}

はじめに

慢性膵炎は強固な疼痛を主訴とするのみならず，周 辺藏器の合併症を伴うことが知られている．コント ロール困難な疼痛の持続あるいは合併症を有する場合 には外科治療の適応となる . 慢性膵炎の外科的治療に は, 病変部の膵切除や膵液ドレナージがあるが, 膵頭 部の1部をくりぬく芯抜きおよび脺体尾部主膵管空腸 吻合術を行うFrey 手術 ${ }^{1}$ は両者を兼ね備えた術式と いえる.今回 ,われわれはF r ey 手術が奏効した膵気管 支瘻を合併した慢性膵炎の1例を経験したので報告す る。

$$
\text { 症例 }
$$

症例 : 40歳, 男性

\section{主訴：背部痛, 呼吸困難}

現病歴 : 平成11年 9 月に背部痛，乾性咳嗽，呼吸困 難を自覚し,近医を受診した .胸部 X 線写真で胸水を 指摘され, 胸水中アミラーゼ値も高値を示しており, また胸腹部 CT 所見より主膵管内膵石 , 仮性膵囊胞の 縦隔進展と診断された。保存的治療中に脺気管支瘻に よる喀血をきたしたため，手術目的で当科紹介入院と なった 。

既往歴 : 18歳時, 虫垂切除術，39歳時，十二指腸潰 瘍穿孔に対し穿孔部閉鎖術が施行された。

飲酒歴 : 日本酒 3〜 5合/日を15年間

家族歴 : 父親が糖尿病

$<2001$ 年 2 月 28日受理 > 別刷請求先 : 藤井 雅和

干 755-8505 宇部市南小串1一1-1 山口大学医学部

第 1 外科学講座
血液生化学検査 : 空腹時血糖値 $141 \mathrm{mg} / \mathrm{dl}$,血清アミ ラーゼ值142.4IU $/ l$,膵アミラーゼ值40.11U $/ l$ といずれ も上昇していた . また , 胸水中アミラーゼ值も19,164 $1 \mathrm{U} / \mathrm{l}$ と著しく上昇していた.軽度の正球性正色素性貧 血を認める他に異常所見はなかった (Table 1).

胸部 X 線写真 : 入院時には右胸腔ドレーンが留置 されており，右胸腔内には胸水の貯留はなかったが， 左下肺野に透過性の低下を認め, 胸水の貯留が疑われ た。

内視鏡的逆行性膵胆管造影 (ERCP) : 主膵管の拡張 は認められなかったが, 膵頭部に10x 6mm の透亮像が あり膵石と考えられた，弚の体部側には主膵管と交通 した4× 3cm の造影斉の貯留像を認めた (Fig.1)．

術前コンピューター断層撮影 (CT) : 腹部は脺頭部 に径2cm の低吸収域を認め，仮性囊胞と考えられた (Fig. 2-1) .また胸部 CT では膵周囲から連続して胸部 下行大動脈左腹側に径 $1 \mathrm{~cm}$ の不整形の空洞を認め, 仮 性膵囊胞の縦隔進展と考えられた (Fig. 2-2) .

気管支ファイバースコピー: 右 B6からやや暗赤色 調の血液の流出を認めた. 右 B6の洗浄液のアミラーゼ 值は10,725IU/l であり，脺気管支瘻による出血である と考えられた。

手術所見 : 平成12年 1月25日開腹術を施行した . 腹 腔内所見は, 膿や腹水の貯留は認めないものの大網の 腹壁への強固な癒着を認めた . 膵被膜は肥厚し硬度も やや増強し，慢性膵炎の所見を呈していた . 頭体部境 界部には頭側へ向け母指等大の青白色部があり，仮性 囊胞と考えられた . 術中超音波検査を施行し主膵管を 
Table 1 Laboratory findings

\begin{tabular}{lc|ll}
\hline A Ib & $3.5 \mathrm{~g} / \mathrm{dl}$ & BUN & $5 \mathrm{mg} / \mathrm{dl}$ \\
T B & $0.9 \mathrm{mg} / \mathrm{dl}$ & Cre & $0.62 \mathrm{mg} / \mathrm{dl}$ \\
$\mathrm{BS}$ & $141 \mathrm{mg} / \mathrm{dl}$ & CRP & $0.87 \mathrm{mg} / \mathrm{dl}$ \\
$\mathrm{Chol}$ & $155 \mathrm{mg} / \mathrm{dl}$ & $\mathrm{RBC}$ & $3101010 / l$ \\
$\mathrm{ChE}$ & $136 \mathrm{IU} / l$ & $\mathrm{Ht}$ & $31.0 \%$ \\
GOT & $25 \mathrm{IU} / l$ & $\mathrm{Hb}$ & $10.6 \mathrm{~g} / \mathrm{dl}$ \\
GPT & $12 \mathrm{IU} / l$ & $\mathrm{WBC}$ & $6,60010^{8} / l$ \\
$\gamma$-GT P & $56 \mathrm{IU} / l$ & $\mathrm{PIt}$ & $26.410^{10} / l$ \\
A LK & $264 \mathrm{IU} / l$ & $\mathrm{Na}$ & $141 \mathrm{mmol} / l$ \\
LDH & $165 \mathrm{IU} / l$ & $\mathrm{~K}$ & $4.3 \mathrm{mmol} / l$ \\
A my & $142.4 \mathrm{IU} / l$ & pleural effusion \\
P-A my & $40.1 \mathrm{IU} / l$ & A my & $19,164 \mathrm{IU} / l$ \\
\hline
\end{tabular}

Fig. 1 ERCP was showing a $4 \times 3 \mathrm{~cm}$ pancreas cyst with accumulation of contrast medium, which leads into the main pancreas duct $(\uparrow)$ and $10 \times 6 \mathrm{~mm}$ pancreatolithiasis $(\uparrow \uparrow)$.

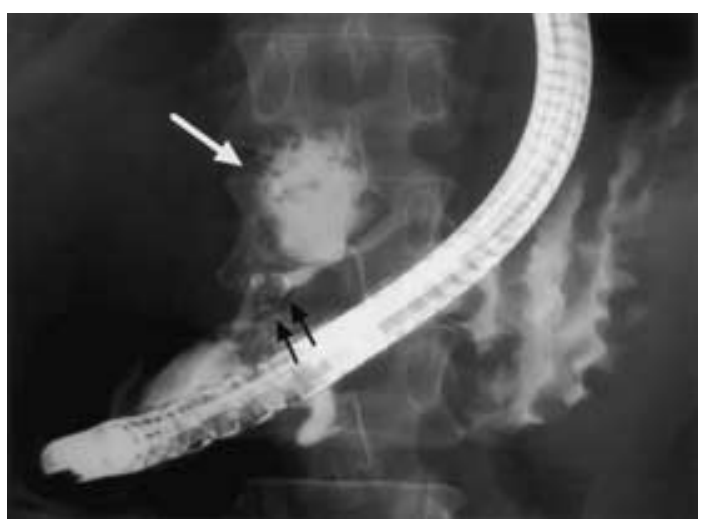

確認した後 , 注射針で穿刺し脺液の逆流を確認し , こ れを目安に腹側面より主膵管を電気メスで長径 $12 \mathrm{~cm}$ ほど横切開した 頭部では脺管減圧と脺石除去のため, 門脈を損傷しないように電気メスを用いて膵実質を直 径3cm core out した .Roux-en $Y$ 再建とし, 主膵管と空 腸全層を4-0モノフィラメントの吸収系にて連続縫合 し，膵管空腸側々吻合術を施行した。

病理組織学的所見 : Core out した膵頭部の膵実質 内に中等度の繊維化を認めるのみであった .

術後 CT : 術後27日目の腹部 CT で, 脺管空腸吻合 部の膵管の拡張はなく，膵液の空腸へのドレナージは 良好であると考えられた .また，胸部 CT では術前に認 められた縦隔内の空洞は消失していた (Fig. 3) .

術後経過：術後の経過は良好で，術後10日目から飲
Fig. 2-1 A bdominal CT was showing a 2cm low density area in the pancreas head.

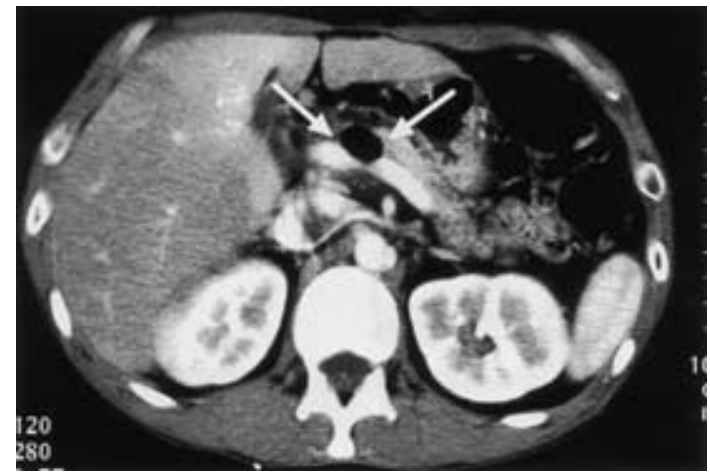

Fig. 2-2 Chest CT was showing a $1 \mathrm{~cm}$ air cavity in the left anterior area of the descending aorta leading from the pancreas.

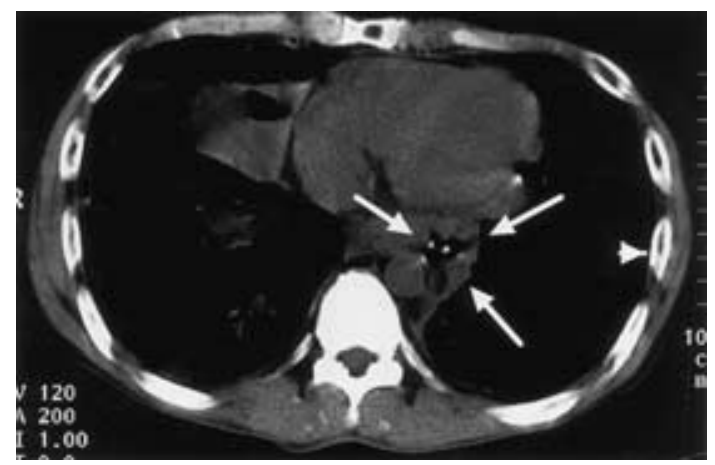

水，術後14日目から食事を開始したが，腹痛などの自 覚症状はまったくなかった，術後31日目に軽快退院し た. 現在外来通院中で，耐糖能も $\mathrm{HbA}_{1 \mathrm{c}}$ が5.7\% と正常 範囲であり, 脺内分泌機能は良好に温存されていた．

$$
\text { 考察 }
$$

慢性膵炎の治療は禁酒や食事など生活習慣の改善, 疼痛コントロールのための薬物療法など内科的治療が 第 1 選択である.しかし薬物療法でコントロール困難 な疼痛の持続あるいは周辺藏器に合併症を有する場合 などに外科的治療の適応がある. 慢性膵炎の手術とし ては, 膵管ドレナージ術と膵切除術とに大別される . 脺管ドレナージ術としては Puestow ら²)の脺尾部切除 兼膵管空腸側々吻合術, Partington ら ${ }^{3)}$ の脺管空腸 側々吻合術などがある . 脺切除術としては脺頭十二指 腸切除術や幽門輪温存膵頭十二指腸切除術，また最近 では十二指腸温存脺頭切除術 ${ }^{4}$ などがある .しかし , 慢 
Fig. 3 Postoperative chest CT was showing no air cavity leading from the pancreas.

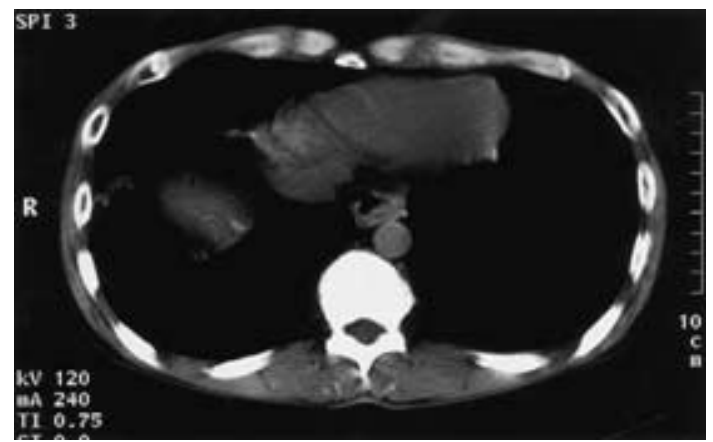

性膵炎という良性疾患の概念からは，膵切除術の場合 には術後晚期における各種代謝機能障害，内外分泌能 の低化を原因とする合併症の発生率や死亡率は高 (い).また，膵頭部に腫瘤形成がある場合や膵石が多数 存在する場合には膵管ドレナージ術のみでは病態の改 善を期待するのは難しい( $)$. 膵頭部の core out を伴う 膵管空腸吻合術である F r ey 手術は1987年この問題を 解決するために考案された ${ }^{11}$.6例に対して手術が施 行され，全例に著明な疼痛の軽減を認め，また術後合 併症もなく，体重も全例術前以上に回復していた . 光 の後のFrey による報告では，疼痛の消失 $74.5 \%$,軽減 $12.8 \%$ ，疼痛改善を認めなかった例は12.8\%であった 。 また，体重増加例も64\%に認めた . 内分泌機能に関し ても, 糖尿病の進行例は11\%であり，良好な成績とい える7). 本邦においてもNetoら ${ }^{5}$ は，疼痛の消失96.7 \% , 体重増加は全例と報告し，さらに内分泌機能にお いても，術前正常であった20例のうち 3例（15\%）に 術後糖尿病を認めるのみで, 食事療法や経口糖尿病薬 でコントロール可能でF r ey の報告とほぼ同樣に良好 な成績であったと述べている．

膵気管支瘻は膵液が直接胸腔内に流入するまれな病 態である.lglehart ら゙によるとこれまでに11例の報告 があり，乥の原因として急性脺炎 (7例)，慢性膵炎 (2例)，外傷性(2例)であった ここれらのうち4例に 手術が行われ（膵体尾部切除術 2 例，脺管空腸吻合術 1例，囊胞胃吻合術 1 例）, 全例治瘾している.また残 り 7 例はドレナージなどで保存的に治療されており， 1例は死亡している.Stenger ら ${ }^{8}$ の報告では ,4 週間以
上の保存的治療で改善しない症例に手術を施行し，良 好な結果が得られている. 膵気管支瘻における手術適 応は, ドレナージや薬物治療などの内科的治療に抵抗 を示す場合と考えられている9 . 自験例はFrey 手術 によって自覚症状，病状などが著明に改善した . 膵気 管支瘻は, 膵管空腸吻合によって膵液ドレナージが効 を奏し, 瘻孔内の圧力が低下し閉鎖したと考えられた 。 さらに, 膵頭部の core out によって膵頭部の膵管減圧 がより強化され，疼痛の消失に有用であったと考えら れた。

以上より，膵頭部の core out を伴う膵管空腸吻合術 であるFrey 手術は，耐糖能も $\mathrm{HbA}{ }_{10}$ が5.7\%で正常範 囲と膵内外分泌能を温存でき，合併症や手術侵襲が少 なく術後QOLにおいて非常に有用であり，膵頭部に 腫瘤や膵石などの病変のある慢性膵炎に対しよい適応 であると考えられた .

$$
\text { 文献 }
$$

1) Frey CF, Smith GJ : Description and Rationale of a New Operation for Chronic Pancreatitis. Pancreas 2 : 701-707, 1989

2) Puestow CW, Gillesby WJ : Retrograde surgical drainage of the pancreas for chronic relapsing pancreatitis. A nn Surg 69 : 898-907, 1958

3) Partington PF, Rochelle RL : Modified Poestow procedure for retrograde of the pancreatic duct. A nn Sug 152 : 1037-1043, 1969

4) Beger HG, Krautzberger W, Bittner $R$ et al : Duodenum-preserving resection of the head of the pancreas in patients with severe chronic pancreatitis. Surgery $97:$ 467-473, 1985

5) Neto FC, 下田光義, Pareja JC ほか : 慢性膵炎に おける十二指腸温存膵頭部切除 (coring-out) を伴 う膵空腸側々吻合術 (Frey 術式). 手術 49: 495-502, 1995

6) 松野正紀, 小針雅男,中村隆司ほか: 慢性膵炎に対 するFrey 手術. 手術 49: 481—487, 1995

7) Iglegart JD, Mansback C, Postlethwait $R$ et al : Pancreaticobronchial Fistula. Gastroenterology $90:$ 759-763, 1986

8) Stenger AM, Knoefel WT, Dahmen $U$ et al : Pancreatico-bronchial fistula with communication to a pseudoaneurysm of the arteria lienalis as a rare complication in chronic pancreatitis. Z Gas troenter ol 36 : 1047-1051, 1998

9) 桜井稔泰, 藤山理世, 大西 尚ほか: 気管支胸膜瘦 による続発性気胸を併発した膵性胸水の1例 . 日 呼吸会誌 $37: 662$-665, 1999 
A Case of Chronic Pancr eatitis with Pancr eatico-bronchial

Fistula Successfully T r eated with Frey's Oper ation

\author{
Masakazu F ujii, T adahiko Enoki, Chizuru Nakay ashiki, T oshihiro Inokuchi, \\ T etsuro Kobay ashi, Shinji Noshima and Kensuke Esato \\ First Department of Surgery, Y amaguchi University School of Medicene
}

A 40-y ear-old man suffering from back pain and dy spnea was successfully treated for chronic alcoholic pancreatitis but continued to have back pain and a dry cough. He was diagnosed with a pancreatic pseudocyst, a fistulous tract reaching into the mediastinum, and pancreatolithiasis. A $9 \times 6 \mathrm{~mm}$ pancreatolithiasis was observed in the pancreas head and a cyst projecting into the main pancreas duct by endoscopic retrograde cholangiopancreatography. A fter a median skin incision, the greater omentum was dissected transversely and the pancreas was ex posed. A fter ultrasonographic confirmation of pancreatolithiasis and the ductal cyst, the stone w as cored out of the pancreas head and a side-to-side longitudinal pancreaticojejunostomy was conducted. T he patient was discharged on postoperative day 31 and the postorerative course was uneventful. T he pseudocyst and fistulous tract disappeared. T he man also had a normal blood glucose level of $\mathrm{HbA}{ }_{10} 5.7 \%$. Key words : chronic pancreatitis, Frey's procedure, pancreatico-bronchial fistula

[Jpn J Gastroenterol Surg 34 : 615-618, 2001]

Reprint requests : Masakazu Fujii First Department of Surgery, Y amaguchi University School of Medicene 1-1-1 Minami-Kogushi, Ube, 755-8505 JA PA N 